\title{
Medical Students Who Prepare for a Lecture Learn More Than Those Who Do Not: An Experimental Study
}

\author{
Hamad Alfahaad ${ }^{1,2^{*}} \quad$ WadhaAlfarwan $^{1,2} \quad$ EmadMasuadi $^{2} \quad$ MohiEldinMagzoub $^{2}$ Henk G. Schmidt ${ }^{2}$ \\ 1.College of Medicine, Najran University, PO box 1988, Najran, Saudi Arabia \\ 2.Medical Education, College of Medicine, King Saud bin Abdulaziz University for Health Sciences, \\ PO box 14611, Riyadh, Saudi Arabia
}

\begin{abstract}
Purpose: Medical students tend to attend lectures unprepared before studying the literature for an examination. Would students not profit more from lectures if they study the literature first?Method: One hundred and two students from a Saudi-Arabian medical school were included in the study. Half of them received a four-page text to be studied before a 15-minutes lecture; the other half received the lecture first and then the text. Knowledge level was tested using a concept retrieval test at three points in time, before the experiment, after reading the text, and after attending the lecture. This enabled studying the effects of the various treatments separately.Results: The mean student-scores were as follows: After lecture-only: $54.7 \pm 23.5$, after reading-only: $45.7 \pm 11.2$, lecture-thenreading: $69.9 \pm 15.8$ and reading-then-lecture: $78.2 \pm 17.4$. The combination of lecture and reading in both groups was statistically significantly different from lecture-only. Reading-then-lecture was significantly better than lecture-then-reading.Conclusion: In contrast to existing practices of students in medical education, it is better to study first before attending a lecture.
\end{abstract}

Keywords: Lectures; self-study; concept retrieval test.

DOI: $10.7176 / \mathrm{JEP} / 11-8-06$

Publication date:March $31^{\text {st }} 2020$

\section{Introduction}

The lecture is perhaps the oldest and still remains the most popular form of teaching. The lecture is an oral presentation of facts and theories on a specific subject, presented to an audience by a lecturer who stands on front of them in an auditorium.

Lecturing as an effective teaching tool has both its defenders and skeptics (Bligh, 1972; Richardson, 2008; Powell, 2003). An obvious advantage of the lecture is that it is cost-effective as compared with instructional methods that employ small-group learning, or require extensive production of learning resources for self-directed learning. A lecture can accommodate large numbers of students at the same time and place. A second perceived advantage is that the lecture may induce a higher level of motivation to study the particular topic. Finally, lectures are suited when difficult topics have to be explained that students cannot master based on self-study (Schmidt et al., 2015).

Students seem to profit from lectures; it has been shown that students who attend lectures have better exam scores than those who are do not attend (Purcell, 2007; Riggs and Blanco, 1994; Sade and Stroud,1982).

Authors suggest that such better achievement emerges because the lecture helps students to distinguish between what is important and what is not important, and the lecturer may clarify misunderstood principles or facts (Riggs and Blanco, 1994 ). However, since such studies are based on simple correlations between attendance and performance, findings may also indicate that better students tend to attend lectures more often than poorer students.

Lectures also have disadvantages. Interaction between teacher and students is often lacking and instruction based on lectures is considered to foster passive learning (Hurst, Wallace, and Nixon, 2013

; Kelly et al., 2005).

Studies have shown that students have an attention span considerably shorter than the length of most lectures, resulting in daydreaming or other extraneous activities (Szpunar, Moulton, and Schacter, 2013). In addition, the limited time allotted to a lecture may not allow to cover all subjects sufficiently. Other critics of the lecture suggest its inappropriateness to cover objectives that requires higher-order mental processing such as problem solving and critical thinking (Bligh,1972).

Furthermore, students may focus their studies only on topics discussed by the lecturer and ignore other topics that need to be covered in the curriculum. Some even suggest that lectures could be replaced by self-study, because it does not make a difference in terms of achievement (Abraham, Dhume, and Diniz,1981; Green, 2002; van Berkel and Schmidt, 2005), or even leads to better learning (Corey, 1934).

In everyday university practice however, lectures do not stand on their own. Most of the time, in addition to attending lectures, students are expected to engage in self-study. Whereas teachers often stress the importance of self-study before students come to the class, students tend to attend lectures unprepared. The lecture is thought to provide hints about the importance of the various subjects and hence attending it before engaging in self-study 
seems more efficient. Furthermore, there is the "information transmission fallacy." Implicit to lecturing is the idea that information can be directly transmitted from one person to another. Therefore, students and teachers alike implicitly seem to believe that most of what the teacher tells students is learned and remembered as it was taught (Schmidt et al., 2015).

However, there may be advantages for self-study before attending a lecture. First, unlike listening to a lecture, self-study allows students to study at their own pace and to repeat parts that they did not initially understand. Second, self-study might provide a framework within which information provided at the lecture may be more easily understood. Third, since the lecturer may assume that the students are already conversant with the material, he or she can concentrate on the really difficult stuff and adapt the lecture to the most pressing concerns of the students.

The study reported in this article is to our knowledge the first in which the timing of self-study in relation to a lecture was experimentally manipulated. Half of our participants studied a text before receiving a lecture on a particular topic, whereas the other half studied the text after the lecture. Since we managed to measure knowledge (gain) three times consecutively, we were in a position to compare the effects of self-study alone, lecturing alone, and the two possible combinations of self-study and lecturing. Since self-study provides more flexibility in learning, we hypothesized that students learn more from a text than from a lecture, and that therefore reading before being lectured begets advantages over the reverse.

\section{Method}

\subsection{Overview}

The present study was an experimental, controlled, pre- and posttest design with multiple comparisons. Students either read a text on psoriasis first, followed by a lecture on the topic, or were lectured first, followed by studying the text. Students' knowledge of the topic was tested before the experiment, after the first activity, and after the second activity.

\subsection{Participants}

The study sample comprised both female and male students in the preclinical phase. All 200 students available at the time of study were invited. Any student who did not accept the invitation or withdrew, who did not attend the lecture, did not read the learning material, or did not take the pre-test or post-test was excluded. The study was conducted at the College of Medicine, King Saud bin Abdulaziz University for the Health Sciences, Riyadh, Saudi Arabia.

The minimum sample size of the study was computed using an online program (http://www.openepi.com/SampleSize/SSMean.htm).Ata significance level of 0.05 , power of $80 \%$, and standard deviation of 5, the minimum size of the sample was 30 students in each group. An expected mean difference of $>5 \%$ was considered meaningfully significant. A random sampling technique was applied, and for increasing precision we included all students who were available during the study conducting period. Therefore, a total of 102 students was included in the study: 51 females and 51 males.

\subsection{Materials}

The text consisted of 957 words, detailing the epidemiology, pathophysiology, types, and treatment of psoriasis. The lecture consisted of a script on the same topic, prepared and presented by the lecturer. It consisted of 36 slides, largely covering the same subjects and enriched with dermatological slides, detailing the different types of psoriasis. The test was a concept retrieval test (CRT). A CRT requires students to write down everything they remember about a particular subject, in the form of a list of concepts, or short power points. The test comprised one question "List all the main concepts related to psoriasis." Two teachers prepared a standard answer comprised of twenty main concepts. A student received one mark for each concept mentioned. CRTs have been demonstrated to have both sufficient reliability and validity (Rotgans, et al., 2018; Yew, Chng, and Schmidt, 2011).

\subsection{Procedure}

Student were randomly assigned to one of the conditions of the experiment. The lecture-then-reading group, consisting of 49 students, received the first CRT, then was lectured, followed by the second CRT. Subsequently, it studied the text for 15 minutes, followed by the third CRT. The reading-then-lecture group, consisting of 53 students, received the first CRT, then studied the text for 15 minutes, followed by the second CRT. Subsequently, it was lectured, followed by the third CRT. The experiment was designed such, that both groups attended the lecture on psoriasis for fifteen minutes at the same time and in the same lecture hall. The difference in size of the groups was caused by post-randomization dropout.

\subsection{Analysis}

Two teachers independently scored the CRTs, based on the list of admissible concepts. Their agreement was $85 \%$. 
Differences were resolved by discussion. The resulting scores were transformed into percentages $(100 \%=$ all 20 concepts correctly retrieved), to facilitate interpretation of the resulting scores, and analyzed using SPSS 20.0 for Windows. Means and standard deviations were computed and submitted to repeated measures analysis of variance (ANOVA). Pair wise comparisons were conducted using ANOVA. Results with an alpha-level $<0.05$ were considered significant.

\subsection{Ethical clearance}

Approval was obtained from King Saud bin Abdulaziz University for the Health Sciences to conduct the study. The purpose of the study was explained to the participants and an agreement covering letter was obtained from them. The participants were guaranteed confidentiality and autonomy. The data were coded for confidentiality and handled only by the first author, so that not to be provided or distributed to someone else without written approval from the participants. Each participant had the right to withdraw from the study at any stage.

\section{Results}

Means and stand deviations by treatments are summarized in Table 1.

\begin{tabular}{lcccc}
\hline \multicolumn{1}{c}{ Treatment } & $\mathrm{N}$ & Pretest CRT & $\begin{array}{c}\text { Posttest CRT } \\
\text { after activity 1 }\end{array}$ & $\begin{array}{c}\text { Posttest CRT } \\
\text { after activity 1 and 2 }\end{array}$ \\
\hline Reading-then-lecture & 53 & $1.79(3.68)$ & $45.66(11.23)$ & $78.21(17.43$ \\
Lecture-then-reading & 49 & $0.61(2.20)$ & $54.69(23.46)$ & $69.90(15.80)$ \\
\hline Total & 102 & $1.23(3.10)$ & $50.00(18.62)$ & $74.22(17.10)$ \\
\hline
\end{tabular}

Table 1. Means and standard deviations for the two experimental conditions (reading-then-lecture and lecturethen-reading) of pretest, posttest after activity 1 (either reading-only or lecture-only), and posttest after both activities (either reading-then-lecture and lecture-then-reading)

A repeated measures ANOVA with CRT as within-group variable and treatment as between-group variable produced the following results: Not surprisingly, the effect of repeatedly measuring achievement over time is large: $\mathrm{F}(2,100)=891.75, \mathrm{p}<.001$. The effect of group membership is $\mathrm{F}(1,101)=.06$, nonsignificant.

More interesting are the pair wise comparisons, of which we only present the crossover findings. Readingonly versus lecture-only: $\mathrm{F}(1,101)=6.30, \mathrm{p}<.05$; reading-then-lecture versus lecture-then-reading: $\mathrm{F}(1,101)=$ $6.33, \mathrm{p}<.05$; reading-only versus lecture-then-reading: $\mathrm{F}(1,101)=80.74, \mathrm{p}<.0001$; and lecture-only versus reading-then-lecture: $\mathrm{F}(1,101)=33.34, \mathrm{p}<.0001$.

These findings suggest that, somewhat surprisingly, attending a lecture-only supports learning better than only reading a relevant text. We assumed that the greater flexibility, afforded by studying a text, would lead to more learning. Post-hoc analysis, however, showed that the lecture contained more concepts relevant to the CRTs than the text. As would be expected, combinations of reading and lecture do much better than reading-only or lecture-only.

More important to the purpose of the present study is that the combination reading-first and then attending a lecture does better than first attending a lecture and then studying a text. This effect is even more outspoken if we compute the knowledge gains indicated by the differences between the CRTs taken after activity 2 and activity 1 . The mean gains for reading-then-lecture are 32.55 (standard deviation 14.03) and for lecture-then-reading are 15.20 (standard deviation 21.50); $\mathrm{F}(1,101)=23.66, \mathrm{p}<.0001$. Participants in the reading-then-lecture group gain more than twice as many concepts than the lecture-then-reading group. This suggests that students in the first group profit far more from the lecture than students in the second group from reading the text.

Post-hoc analyses of covariance (ANCOVA) for both gender and pre-test score were conducted to check whether randomization had succeeded. The results were not affected by the gender of the students, nor by the pretest, nor by a combination of both.

\section{Discussion}

Students tend to postpone self-study of a particular topic until after receiving a lecture. There may be several reasons why they do so: it may be an issue of procrastination (Steel, 2007), or they may perceive attending a lecture first as a more efficient learning strategy: if you hear the teacher lecture, you know better what to focus on during self-study. Teachers however, prefer students to read first before they come to the classroom. The purpose of the present study was to find out whether the timing of self-study (before or after a lecture) would make any difference. To that end, we required 102 medical students, in a tightly controlled experiment, to study a text on psoriasis for the same amount of time either before or after attending a lecture on the same subject. We found that reading before a lecture led to larger knowledge gains than the reverse, despite of the fact that students profited more from a lecture-only condition than from a reading-only condition.

Our findings bear some resemblance to findings produced by studies within the "flipped-classroom" framework. In the flipped classroom, students first engage in self-study, from resource materials that may or may not include videotaped lectures, before they come to class. Classroom time is then spent on answering questions 
and engaging in exercises, to encourage active learning and, henceforth, more elaborate processing (Bishop and Verleger, 2013; McLaughlin et al., 2014; O'Flaherty and Phillips, 2015; Tune, Sturek and Basile, 2013). These studies, mostly conducted in the actual classroom and employing a historical control group, demonstrate that selfstudy plus classroom activity leads to larger learning gains than the conventional approach in which lecturing tends to precede self-study. Moravec et al., (2010) for instance, tested this approach in a large introductory biology course. Four to five slides from 2007/8 were removed from each of three lectures in 2009 and the information introduced in preclass worksheets or narrated PowerPoint videos. In class, time created by shifting lecture material to learn-before-lecture assignments was used to engage students in application of their new knowledge. Mean increase in performance was more than twenty percent across the six learn-before-lecture-related questions. However, since in these studies, the nature of the classroom activities as well as the timing of the self-study change, it is unclear what exactly leads to better learning: Is it the timing of the self-study or the more active classroom that makes the difference? Since in our study, the classroom activity was held constant over the conditions of the experiment as was studying the text, we could attribute the large learning gains to the timing of the self-study only.

Why does learning before a lecture affords such learning gains over the opposite strategy? We assume here that reading at one's own pace, with the possibility of rereading parts not easily understood, increases the integration of the new material with prior knowledge, a cognitive process essential for any learning to occur (Bransford, Brown and Cocking, 2000; Hewson, 1982). Even when, under time restriction, fewer new concepts are learned through text (as seems the case in our study), the concepts that are learned are processed more elaborately, therefore enabling a better understanding of what new ideas the lecture has to offer as well. Those who attend a lecture first, do not have the same opportunity of integrating new concepts with prior knowledge because they are dependent on the pace of the lecturer and have no opportunity to review some of the material beyond what the lecturer him- or herself reviews. In summary, students can only optimally profit from a lecture if prior knowledge has been sufficiently activated and elaborated upon.

Our study and its findings clearly have limitations. The first is that the learning cycle, in reality usually consisting of several hours of lectures and several hours of self-study, for the sake of tight control over the conditions of the experiment was reduced to 15 minutes of self-study and 15 minutes of lecturing. It is possible that such brief experiences do not fully represent the complexity of learning in advanced knowledge domains. More important perhaps is that we had to restrict self-study, an activity, unlike lectures, that is normally unrestricted in time. It cannot be excluded that students would have made up for poorer preparation caused by the lecture-first approach by spending more time on studying the text. A follow-up experiment should take this possibility into account and should be designed such that students are free to spend as much time as they feel they need on self-study.

\section{Conclusion}

In contrast to existing practices of students in medical education, it is better for students to study first before attending a lecture.

\section{Acknowledgements}

We are thankful to Dr. Omair and Dr. Bargo who facilitated in conducting the study. Furthermore, we are thankful to the medical students who participated in this study.

\section{References}

- $\quad$ Abraham,G.J.S., Dhume, V.G. and Diniz, R.S. (1981), Comparison of didactic lecture, self reading and self instruction as learning methods in medical students of western India. Medical Education, 15: 222-225. doi:10.1111/j.1365-2923.1981.tb02636.x

- Bishop, J. L., \& Verleger, M. (2013), " The flipped classroom: A survey of the research. Paper presented at the 120th ASEE Annual Conference \& Exposition, Atlanta, GA. (Vol. 30, pp. 1-18).

- Bligh, D. (1972). What's The Use Of Lectures?. Harmondsworth: Penguin.

- Bransford, J., Brown, A., \& Cocking, R. (Eds.),( 2000), How people learn: Brain, mind, experience, and school. Washington DC: National Academy Press [National Research Council].

- Corey, S. (1934), Learning from lectures vs. learning from readings. Journal of Educational Psychology, 25(6), pp.459-470.

- Green, J.,. (2002), Replacing lectures by textbased flexible learning: students' performance and perceptions. Journal of Biological Education, 36(4), pp.176-180.

- Hewson, P. (1982), A Case Study of Conceptual Change in Special Relativity: The Influence of Prior Knowledge in Learning. European Journal of Science Education, 4(1), pp.61-78.

- Hurst, B., Wallace, R. and Nixon, S. (2013), The Impact Of Social Interaction On Student Learning. Reading Horizons (Online),. 52(4): p. 375. 
Available at: https://scholarworks.wmich.edu/cgi/viewcontent.cgi

- $\quad$ Kelly, P., Haidet, P., Schneider, V., Searle, N., Seidel, C. and Richards, B. (2005), A Comparison of In-Class Learner Engagement Across Lecture, Problem-Based Learning, and Team Learning Using the STROBE Classroom Observation Tool. Teaching and Learning in Medicine, 17(2), pp.112-118.

- McLaughlin, J., Roth, M., Glatt, D., Gharkholonarehe, N., Davidson, C., Griffin, L., Esserman, D. and Mumper, R. (2014), The Flipped Classroom. Academic Medicine, 89(2), pp.236-243.

- Moravec, M., Williams, A., Aguilar-Roca, N. and O'Dowd, D. (2010), Learn before Lecture: A Strategy That Improves Learning Outcomes in a Large Introductory Biology Class. CBE-Life Sciences Education, 9(4), pp.473-481.

- O'Flaherty, J. and Phillips, C. (2015), The use of flipped classrooms in higher education: A scoping review. The Internet and Higher Education, 25, pp.85-95.

- $\quad$ Powell, K. (2003), Spare me the lecture. Nature, 425(6955), pp.234-236.

- Purcell, P.(2007), Engineering Student Attendance at Lectures: Effect on Examination Performance. In: International Conference on Engineering Education - ICEE 2007. Paper presented at the International Conference on Engineering Education. http://icee2007.dei.uc.pt/proceedings/papers/107.pdf

- Richardson, D. (2008), Don't dump the didactic lecture; fix it. Advances in Physiology Education, 32(1), pp.23-24.

- $\quad$ Riggs, J.W. \& Blanco, J.D. (1994), Is there a relation between student lecture attendance and clinical science subject examination score? Obstetrics and Gynaecology, 84(2), 311-313.

- Rotgans, J.I., et al., Reliability and validity of a new measure of conceptual knowledge: The concept retrieval test. submitted, 2018.

- $\quad$ Sade, R. and Stroud, M. (1982), Medical student attendance at lectures. Academic Medicine, 57(3), pp.1912.

- Schmidt, H., Wagener, S., Smeets, G., Keemink, L. and van der Molen, H. (2015), On the Use and Misuse of Lectures in Higher Education. Health Professions Education, 1(1), pp.12-18.

- Steel, P. (2007), The nature of procrastination: A meta-analytic and theoretical review of quintessential selfregulatory failure. Psychological Bulletin, 133(1), pp.65-94.

- Szpunar, K., Moulton, S. and Schacter, D. (2013), Mind wandering and education: from the classroom to online learning. Frontiers in Psychology, 4.

- Tune, J., Sturek, M. and Basile, D. (2013), Flipped classroom model improves graduate student performance in cardiovascular, respiratory, and renal physiology. Advances in Physiology Education, 37(4), pp.316-320.

- $\quad$ van Berkel, H. and Schmidt, H. (2005), On the Additional Value of Lectures in a Problem-Based Curriculum. Education for Health, 18(1), pp.45-61.

- Yew, E., Chng, E. and Schmidt, H. (2011), Is learning in problem-based learning cumulative?. Advances in Health Sciences Education, 16(4), pp.449-464. 